\title{
Guidelines
}

European

Thyroid Journal
Eur Thyroid J 2016;5:9-26

DOI: $10.1159 / 000443828$
Received: October 5, 2015

Accepted after revision: January 5, 2016

Published online: March 2, 2016

\section{The 2016 European Thyroid Association/European Group on Graves' Orbitopathy Guidelines for the Management of Graves' Orbitopathy}

\author{
Luigi Bartalena $^{a}$ Lelio Baldeschi ${ }^{b}$ Kostas Boboridis ${ }^{c}$ Anja Eckstein ${ }^{d}$ George J. Kahaly ${ }^{e}$ \\ Claudio Marcoccif ${ }^{\text {Petros Perros }}{ }^{g}$ Mario Salvi $^{\text {h }}$ Wilmar M. Wiersinga ${ }^{i}$ \\ on behalf of the European Group on Graves' Orbitopathy (EUGOGO)
}

aDepartment of Clinical and Experimental Medicine, University of Insubria, Endocrine Unit, Ospedale di Circolo, Varese, Italy; ${ }^{b}$ Department of Ophthalmology, Hospital Saint Luc, Catholic University of Louvain, Brussels, Belgium; ${ }^{\circ}$ Ophthalmology Department, Aristotle University of Thessaloniki, Thessaloniki, Greece; ${ }^{d}$ Zentrum für Augenheilkunde, Universitätsklinikum

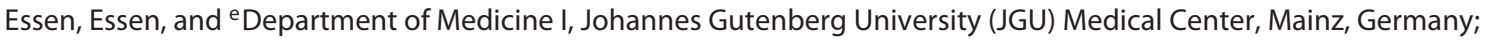
${ }^{f}$ Department of Clinical and Experimental Medicine, University of Pisa, Pisa, Italy; ${ }^{9}$ Department of Endocrinology, Newcastle upon Tyne Hospitals NHS Foundation Trust, Newcastle upon Tyne, UK; ${ }^{\text {h } G r a v e s ' ~ O r b i t o p a t h y ~ C e n t e r, ~ E n d o c r i n o l o g y, ~ F o n d a z i o n e ~}$ Ca' Granda IRCCS, University of Milan, Milan, Italy; 'Department of Endocrinology and Metabolism, Academic Medical Center, University of Amsterdam, Amsterdam, The Netherlands

\section{Key Words}

Cyclosporine - Eyelid surgery · Glucocorticoids · Graves' orbitopathy - Orbital decompression - Orbital radiotherapy . Rituximab $\cdot$ Selenium $\cdot$ Squint surgery

\footnotetext{
Abstract

Graves' orbitopathy (GO) is the main extrathyroidal manifestation of Graves' disease, though severe forms are rare. Management of GO is often suboptimal, largely because available treatments do not target pathogenic mechanisms of the disease. Treatment should rely on a thorough assessment of the activity and severity of GO and its impact on the patient's quality of life. Local measures (artificial tears, ointments and dark glasses) and control of risk factors for progression (smoking and thyroid dysfunction) are recommended for all patients. In mild GO, a watchful strategy is
}

usually sufficient, but a 6-month course of selenium supplementation is effective in improving mild manifestations and preventing progression to more severe forms. High-dose glucocorticoids (GCs), preferably via the intravenous route, are the first line of treatment for moderate-to-severe and active GO. The optimal cumulative dose appears to be $4.5-5 \mathrm{~g}$ of methylprednisolone, but higher doses (up to $8 \mathrm{~g}$ ) can be used for more severe forms. Shared decision-making is recommended for selecting second-line treatments, including a second course of intravenous GCs, oral GCs combined with orbital radiotherapy or cyclosporine, rituximab or watchful waiting. Rehabilitative treatment (orbital decompression surgery, squint surgery or eyelid surgery) is needed in the majority of patients when $\mathrm{GO}$ has been conservatively managed and inactivated by immunosuppressive treatment.

(C) 2016 European Thyroid Association Published by S. Karger AG, Basel

\begin{tabular}{ll}
\hline KARGER & $\begin{array}{l}\text { @ 2016 European Thyroid Association } \\
\text { Published by S. Karger AG, Basel }\end{array}$ \\
$\begin{array}{l}\text { E-Mail karger@karger.com } \\
\text { www.karger.com/etj }\end{array}$ &
\end{tabular}

Prof. Luigi Bartalena

Department of Clinical and Experimental Medicine

University of Insubria, Endocrine Unit, Ospedale di Circolo

Viale Borri 57, IT-21100 Varese (Italy)

E-Mail luigi.bartalena@ uninsubria.it 


\section{Introduction}

In 2008, EUGOGO published a consensus statement on the management of Graves' orbitopathy (GO) simultaneously in the European Journal of Endocrinology and in Thyroid [1,2]. The statement was received very well [3] and has been in widespread use ever since. Guidelines for the management of hyperthyroidism by the American Thyroid Association and American Association of Clinical Endocrinologists were published in 2011; recommendations were made on how hyperthyroidism should be managed in patients with GO, though not on the treatment of GO itself [4]. A number of randomized clinical trials on the treatment of GO have been published in the last few years, and their outcome has influenced substantially the management of GO patients. Consequently, the European Thyroid Association (ETA) commissioned EUGOGO to provide guidelines for the management of GO.

New epidemiological studies provide fairly consistent figures on the prevalence and incidence of GO in the general population and in patients presenting with Graves' hyperthyroidism. The incidence of Graves' hyperthyroidism in the general population of Sweden is 210 per million per year, with a female:male ratio of 3.9:1 and a peak incidence between 40 and 60 years [5]. The incidence of GO is 42.2 per million per year $(20.1 \%$ of the incidence of Graves' hyperthyroidism) [5]. In Denmark, the incidence of moderate-to-severe and very severe GO is 16.1 per million per year in the general population, with a female:male ratio of 5:1 and a peak incidence between 40 and 60 years [6]. The prevalence of moderate-to-severe and very severe GO in patients with Graves' hyperthyroidism was $4.9 \%$ in the Danish study, which was not dissimilar from the $6.1 \%$ observed in a single-center study in Italy [7]. The latter study is of much clinical interest because it clearly demonstrates that most patients with Graves' hyperthyroidism $(>80 \%)$ without GO at presentation who are treated with antithyroid drugs do not develop GO after an 18-month follow-up and that mild GO disappears spontaneously in the majority of cases. A study comparing characteristics of referrals to EUGOGO centers reveals a secular trend to less active and less severe GO in patients referred in 2012 as compared to 2000 [8].

\section{Methods}

\section{Literature Search}

Data acquisition was based on PubMed search strategies, with particular regard to papers published after the publication of the previous EUGOGO consensus statement (2008-2015) [1, 2]. Fur- thermore, the list of references of relevant citations and chapters of major textbooks were evaluated for any additional appropriate citation.

\section{Grading}

The GRADE (Grading of Recommendations, Assessment, Development, and Evaluation) system was used to make recommendations and express the quality of the evidence [9]. The working group used the following coding system: (1) indicates a strong recommendation and is associated with the phrase 'we recommend'; (2) denotes a weak recommendation and is associated with the phrase 'we suggest'. Evidence grading: $\varnothing \bigcirc \bigcirc \bigcirc=$ very low quality; $\varnothing \varnothing \bigcirc \bigcirc=$ low quality; $\varnothing \varnothing \varnothing \bigcirc=$ moderate quality, and $\varnothing \varnothing \varnothing \varnothing=$ high quality. The draft was discussed by the whole EUGOGO group and then posted on the ETA website for 2 weeks inviting comments from ETA members.

\section{Recommendations}

A summary of the recommendations is presented in table 1 .

\section{What Should Be the Clinicians' General Approach to}

\section{Patients with GO?}

Multidomain quality of life (QoL) surveys (e.g. SF-36) show that people with GO have substantially reduced QoL, equivalent to having diabetes or certain cancers [10]. Optimal treatment has been shown to improve QoL in such patients, using a validated, GO-specific QoL tool (GOQoL) [11]. Direct and indirect costs (due to disability and/or unemployment) are significant [12]. To achieve best outcomes, clinicians need to provide a patient-focused comprehensive plan with due attention not only to the clinical components of the disease, but also to the impact of GO on the individual's QoL and psychosocial well-being.

\section{Recommendation}

1 We recommend a patient-focused approach to the treatment of patients with $\mathrm{GO}$, which encompasses the effects of the disease and its treatment on QoL and psychosocial well-being. Use of GOQoL, a diseasespecific and validated tool, is recommended in routine clinical practice and is available in several languages (www.eugogo.eu). $(1, \varnothing \varnothing \bigcirc \bigcirc)$

Why and How Should Activity and Severity of GO Be Assessed?

Selecting the most appropriate treatment for individual patients depends on the activity and severity of the eye
Bartalena et al. 
Table 1. Summary of recommendations

Recommendations

Strength of recommendation and level of evidence

1 General

We recommend a patient-focused approach to the treatment of

$1, \varnothing \varnothing \bigcirc \bigcirc$ patients with GO, which encompasses the effects of the disease and its treatment on QoL and psychosocial well-being. Use of GOQoL, a disease-specific and validated tool, is recommended in routine clinical practice and is available in several languages (www.eugogo.eu).

2 Assessment

We recommend that activity and severity of GO be assessed $1, \varnothing \varnothing \varnothing \bigcirc$ according to standardized criteria and GO be categorized as active or inactive and as mild, moderate to severe or sight threatening, as listed in table 2.

3 Specialized centers We recommend that primary-care physicians, general practitioners, $1, \varnothing \varnothing \bigcirc \bigcirc$ general internists and specialists should refer patients with GO to combined thyroid-eye clinics or specialized centers providing endocrinological and ophthalmological expertise - except for the mildest cases improving with normalizing thyroid status and local lubricants.

4 Quit smoking

We recommend that physicians urge all patients with Graves' hyperthyroidism, irrespective of the presence/absence of GO, to refrain from smoking, if necessary with the help of specialized smoking cessation programs or clinics.

5 Thyroid dysfunction

6 Steroid prophylaxis
We recommend that euthyroidism be promptly restored and stably maintained in all patients with GO.
We recommend that oral prednisone prophylaxis, starting with a daily dose of $0.3-0.5 \mathrm{mg}$ prednisone $/ \mathrm{kg}$ body weight, be given in radioiodine-treated patients at high risk of progression or de novo development of GO. Lower-dose prednisone can be used in lowrisk patients. Patients with inactive GO can safely receive radioiodine without steroid cover, as long as hypothyroidism is avoided, if other risk factors for GO progression, particularly smoking, are absent.

We recommend that all patients with GO be evaluated for ocular surface disease and treated extensively with nonpreserved artificial tears with osmoprotective properties at all times in the course of their disease unless corneal exposure requires the higher protection that gels or ointment can offer especially at nighttime.

8 Mild GO

We recommend that mild GO be treated with local treatments and general measures to control risk factors; if the impact of the disease on QoL outweighs risks, then immunosuppressive therapy (for active GO) or rehabilitative surgery (for inactive GO) may be justified.

9 Selenium supplementation for mild GO

We recommend that a 6-month selenium supplementation be given to patients with mild GO of relatively short duration, because it improves eye manifestations and QoL and prevents GO progression to more severe forms.

10 First-line treatment for moderate-to-severe and active GO
We recommend that high-dose intravenous GCs be considered as first-line treatment for moderate-to-severe and active GO. Intravenous GC therapy should be performed in experienced centers that can safely manage potentially serious adverse events.
$1, \varnothing \varnothing \varnothing \varnothing$

$1, \varnothing \varnothing \varnothing \varnothing$

$1, \varnothing \varnothing \varnothing \bigcirc$

$1, \varnothing \varnothing \varnothing \bigcirc$

\section{$1, \varnothing \varnothing \varnothing \bigcirc$}

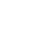


Table 1 (continued)

Recommendations

Strength of recommendation and level of evidence

11 Cumulative dose of intravenous GCs 1
We recommend that the cumulative dose of intravenous GCs should not exceed $8.0 \mathrm{~g}$ and that GO patients with evidence of recent viral hepatitis, significant hepatic dysfunction, severe cardiovascular morbidity or psychiatric disorders should not be administered intravenous GCs; diabetes and hypertension should be well controlled before starting treatment.

12 Cumulative dose of intravenous GCs 2

We recommend that an intermediate-dose schedule of methylprednisolone, i.e. a starting dose of $0.5 \mathrm{~g}$ once weekly for 6 weeks, followed by $0.25 \mathrm{~g}$ once weekly for 6 weeks ( $4.5 \mathrm{~g}$ cumulative dose) in most cases of moderate-to-severe and active GO. High-dose regimens, i.e. a starting dose of $0.75 \mathrm{~g}$ once weekly for 6 weeks, followed by $0.5 \mathrm{~g}$ once weekly for 6 weeks ( $7.5 \mathrm{~g}$ cumulative dose) should be reserved for the worst cases within the moderate-tosevere spectrum.

13 GC withdrawal
We suggest that clinicians should monitor each individual patient receiving GC therapy for response to treatment and adverse effects. When side effects outweigh benefits, clinicians should consider withdrawal of GC treatment in favor of another modality or watchful monitoring.
14 Second-line treatments for moderate-to-severe and active GO

15 Rehabilitative surgery
We recommend shared decision-making as an appropriate approach to select a second-line therapy in patients with moderateto-severe and active GO.
$1, \varnothing \varnothing \bigcirc \bigcirc$

$1, \varnothing \varnothing \varnothing \varnothing$

\section{$2, \varnothing \varnothing \bigcirc \bigcirc$}

We recommend that elective rehabilitative surgery be offered to patients with GO when the disease is associated with a significant $1, \varnothing \varnothing \bigcirc \bigcirc$ impact on visual function or QoL after the disease has been inactive for at least 6 months. If more than one surgical procedure is required, orbital decompression should precede squint surgery and be followed by lid surgery. Patients should be referred to specialized centers and specialized surgeons able to tailor different possible surgeries to the specific need of the individual patient.

16 Treatment of sightthreatening GO 1

17 Treatment of sightthreatening GO 2
We recommend that severe corneal exposure be treated medically or by means of progressively more invasive surgeries as soon as possible in order to avoid progression to corneal breakdown. The latter should be immediately addressed surgically.

We recommend that DON be treated immediately with very high doses of intravenous GCs (500-1,000 mg of methylprednisolone for 3 consecutive days or on alternate days during the 1st week), and urgent orbital decompression be performed if response is absent or poor within 2 weeks. Recent-onset choroidal folds and eyeball subluxation should undergo orbital decompression as soon as possible. If DON has resolved or improved after 2 weeks, pulses of weekly intravenous methylprednisolone should be continued as described for the management of moderate-to-severe and active GO. 
Table 2. Assessment of GO activity and severity

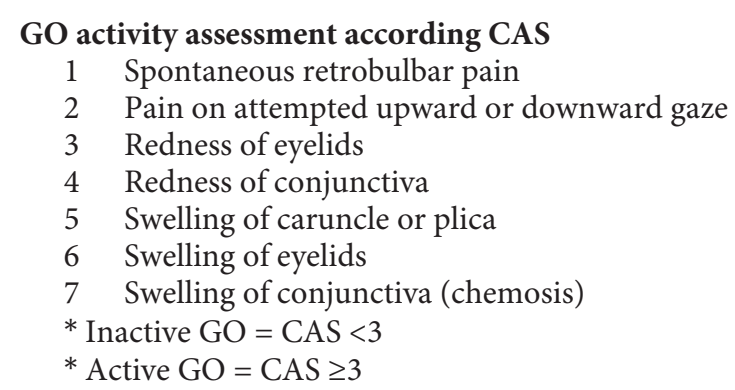

\section{GO severity assessment according to NOSPECS}

No signs or symptoms

Only signs, no symptoms: lid aperture (distance between lid margins in $\mathrm{mm}$ with patient looking in primary position, sitting relaxed, with distant fixation)

Soft tissue involvement: swelling/redness of the eyes

Proptosis: exophthalmos (in mm: using the same Hertel exophthalmometer and same intercanthal distance for an individual patient)

Extraocular muscle involvement: eye muscle ductions in degrees; subjective diplopia score - intermittent (i.e. diplopia when tired or when first awakening), inconstant (i.e. diplopia at extremes of gaze) and constant (i.e. continuous diplopia in primary or reading position)

Corneal involvement: absent/punctuate keratopathy, ulcer

Sight loss (due to optic nerve involvement): best-corrected visual acuity, color vision, optic disk, relative afferent papillary defect, visual fields (if optic nerve compression is suspected)

\section{GO severity assessment according to EUGOGO}

\section{* Mild GO}

Patients whose features of GO have only a minor impact on daily life insufficient to justify immunosuppressive or surgical treatment. They usually have one or more of the following: minor lid retraction $(<2 \mathrm{~mm})$, mild soft-tissue involvement, exophthalmos $<3 \mathrm{~mm}$ above normal for race and gender, no or intermittent diplopia and corneal exposure responsive to lubricants

* Moderate-to-severe GO

Patients without sight-threatening GO whose eye disease has sufficient impact on daily life to justify the risks of immunosuppression (if active) or surgical intervention (if inactive). They usually have two or more of the following: lid retraction $\geq 2 \mathrm{~mm}$, moderate or severe soft-tissue involvement, or exophthalmos $\geq 3 \mathrm{~mm}$ above normal for race and gender, inconstant or constant diplopia

* Sight-threatening GO (very severe GO) Patients with DON and/or corneal breakdown changes. Activity is easily measured by the clinical activity score (CAS) [13]. A CAS $\geq 3 / 7$ is indicative of active GO. Severity is rated as mild, moderate to severe and sight threatening (or very severe). Criteria for activity and severity assessment are reported in table 2 and have not been changed since 2008 [1,2].

\section{Recommendation}

2 We recommend that activity and severity of GO be assessed according to standardized criteria and that GO be categorized as active or inactive and as mild, moderate to severe or sight threatening, as listed in table 2 . $(1, \varnothing \varnothing \varnothing \bigcirc)$

Should All Patients with GO Be Referred to Specialized Centers or Thyroid-Eye Clinics?

GO appears to be less frequent and milder in patients with newly diagnosed Graves' hyperthyroidism now than some years ago [7] and rarely progressive to more severe forms [14]. Also, patients referred to tertiary referral centers have less severe and, more often, inactive GO than in the past [8]. These trends may reflect earlier diagnosis of GO and more effective management strategies of Graves' disease by endocrinologists and ophthalmologists, and underscore the role of specialized centers for early clinical care of these patients. Referral patterns vary among countries and health care systems, and further delineation of pathways of care by national bodies may facilitate this progress [15]. On the other hand, there are still patients presenting with recurrences of inflammatory signs of GO and complications due to inadequate evaluation of clini$\mathrm{cal}$ and imaging features of GO and inappropriate treatment strategies [16]. In a large nationwide survey in the $\mathrm{UK}$, only $56 \%$ of responders were satisfied with the treatment they received for GO; however, those who had attended a specialist GO clinic were more satisfied than those who had not attended a specialist clinic (67 vs. 52\%, $\mathrm{p}<0.05)$ [17].

\section{Recommendation}

3 We recommend that primary-care physicians, general practitioners, general internists and specialists should refer patients with GO to combined thyroid-eye clinics or specialized centers providing endocrinological and ophthalmological expertise - except for the mildest cases improving with normalizing thyroid status and local lubricants. $(1, \varnothing \varnothing \bigcirc \bigcirc)$ 
Table 3. Evidence supporting a negative effect of smoking habits on GO

\begin{tabular}{ll}
\hline Finding & Type of study \\
\hline $\begin{array}{l}\text { Higher prevalence of smokers in Graves' patients with GO than in those } \\
\text { without GO }\end{array}$ & Observational study \\
\hline Smokers tend to have more severe GO & Consecutive entry case-control study \\
\hline $\begin{array}{l}\text { Smokers are more likely to have progression or de novo occurrence of GO } \\
\text { after radioiodine treatment }\end{array}$ & Randomized clinical trial \\
$\begin{array}{l}\text { Smoking delays or worsens the outcome of immunosuppressive treatment } \\
\text { for GO }\end{array}$ & $\begin{array}{l}\text { Randomized clinical trial } \\
\text { Prospective study }\end{array}$ \\
$\begin{array}{l}\text { Refraining from smoking might reduce the risk of developing } \\
\text { exophthalmos and diplopia }\end{array}$ & Retrospective study \\
\hline
\end{tabular}

\section{How Should Risk Factors for GO Occurrence or Progression Be Managed? \\ Smoking}

The association between smoking and GO is well established [18], including the following observations: (i) smokers have more severe GO than nonsmokers [19, 20]; (ii) smokers are more likely to show progression or de novo occurrence of GO after radioiodine treatment [21, 22]; (iii) smoking delays or worsens the outcome of immunosuppressive treatment for GO $[23,24]$, and (iv) in a retrospective study, smoking cessation was associated with a better outcome of GO (table 3) [25]. Accordingly, all patients with Graves' hyperthyroidism, irrespective of the presence or absence of GO, should be urged to quit smoking.

\section{Recommendation}

4 We recommend that physicians urge all patients with Graves' hyperthyroidism, irrespective of the presence/ absence of GO, to refrain from smoking, if necessary with the help of specialized smoking cessation programs or clinics.

$(1, \varnothing \varnothing \varnothing \bigcirc)$

\section{Thyroid Dysfunction and Treatment}

Restoration and maintenance of euthyroidism is imperative in the presence of GO, because both hyper- and hypothyroidism have a negative impact on GO (table 4) $[26,27]$. Antithyroid drugs and thyroidectomy per se do not appear to affect the natural course of GO (table 5) $[21,28]$. Radioiodine treatment confers a small, but definite risk of exacerbation or de novo development of GO $[21,29,30]$, particularly in smokers, in severe hyperthyroidism (high free thyroid hormone levels and/or TSH
Table 4. Evidence supporting a negative effect of thyroid dysfunction on GO

\begin{tabular}{llc}
\hline Finding & Type of study & Ref. \\
\hline $\begin{array}{l}\text { Restoration of euthyroidism with } \\
\text { antithyroid drugs is associated } \\
\text { with an improvement in GO }\end{array}$ & Prospective study & 27 \\
\hline $\begin{array}{l}\text { Occurrence of GO may be } \\
\begin{array}{l}\text { associated with uncontrolled } \\
\text { hypothyroidism }\end{array}\end{array}$ & $\begin{array}{l}\text { Retrospective study } \\
\text { Prospective study }\end{array}$ & 26 \\
$\begin{array}{lll}\text { Late correction of hypothyroidism } \\
\text { after radioiodine treatment is asso- } \\
\text { ciated with increased risk for GO }\end{array}$ & Retrospective study & 36 \\
\hline
\end{tabular}

receptor autoantibodies) $[22,30]$ and hyperthyroidism of recent onset (table 5) [31]. This detrimental effect can be nearly always prevented in patients at risk by oral prednisone prophylaxis given concomitantly with radioiodine treatment. The original schedule used a starting dose of $0.3-0.5 \mathrm{mg}$ prednisone $/ \mathrm{kg}$ body weight per day, and duration of treatment was 3 months [21]. It was subsequently shown that a 6-week course using lower doses (starting dose, $0.2 \mathrm{mg}$ prednisone $/ \mathrm{kg}$ body weight per day) was equally effective (table 5) [32-34]. However, a recent randomized prospective study from Japan showed that the low-dose oral prednisone schedule may not always be sufficient [35]. Vigilance is required to anticipate and prevent thyroid dysfunction after radioiodine treatment; if dysthyroidism occurs, it should be corrected promptly (table 4) [36,37]. Antithyroid drugs, thyroidectomy and radioiodine treatment (with steroid prophylaxis if indicated) are effective treatments for hyperthyroidism, and there is no evidence of a substantial 
Table 5. Effect of treatments for Graves' hyperthyroidism on GO

\begin{tabular}{lll}
\hline Finding & Type of study & Ref. \\
\hline $\begin{array}{l}\text { No modification of natural history of GO with antithyroid drugs } \\
\text { (possible indirect effect due to correction of hyperthyroidism) }\end{array}$ & $\begin{array}{l}\text { Case-control } \\
\text { prospective study }\end{array}$ & 28 \\
\hline $\begin{array}{l}\text { Risk of occurrence/progression of GO after radioiodine treatment in } \\
\text { at-risk patients (preexisting GO, smoker, recent-onset GO) }\end{array}$ & Randomized clinical trial & Randomized clinical trial \\
& Meta-analysis & 21 \\
\hline Occurrence/progression of GO after radioiodine in at-risk patients is & Retrospective study & 30 \\
usually prevented by concomitant oral prednisone (steroid prophylaxis) & Retrospective study & 31 \\
\hline No modification of natural history of GO after thyroidectomy & Meta-analysis & 21 \\
\hline
\end{tabular}

difference on the impact that they have on GO. The choice between these three options depends on the individual circumstances of patients and their preference [38].

\section{Recommendations}

5 We recommend that euthyroidism be promptly restored and stably maintained in all patients with GO. $(1, \varnothing \varnothing \varnothing \varnothing)$

6 We recommend that oral prednisone prophylaxis, starting with a daily dose of $0.3-0.5 \mathrm{mg}$ prednisone $/ \mathrm{kg}$ body weight, be given in radioiodine-treated patients at high risk of progression or de novo development of GO. Lower-dose prednisone can be used in low-risk patients. Patients with inactive GO can safely receive radioiodine without steroid cover, as long as hypothyroidism is avoided, if other risk factors for GO progression, particularly smoking, are absent.

$(1, \varnothing \varnothing \varnothing \varnothing)$

\section{The Rationale for the Use of Topical Treatments at}

\section{All Times in the Course of GO}

Ocular surface inflammatory disease and dry eye are frequent findings in patients with Graves' hyperthyroidism even before the onset of overt GO [39-43]. In GO, increased palpebral fissure width, exophthalmos, blink rate, lid lag, lagophthalmos, deficit in elevation and poor Bell's phenomenon can all potentially cause drying of the ocular surface. According to the results of a prospective case series of 17 patients [44], the damage to the ocular surface depends mainly on widened palpebral fissure, which increases ocular surface evaporation resulting in an elevated tear film osmolarity similar to that of kerato- conjunctivitis sicca. Rose bengal and lissamine green staining clearly demonstrated a significant presence of drying epithelial cells in early as well as in late GO patients compared to controls. Additionally, a significantly low break-up time was found, though limited to late GO patients [45].

When active GO has been specifically studied, ocular surface damage correlated significantly with a reduced tear secretion. The lacrimal gland physiologically expresses the TSH receptor, which, in active GO, can bind with circulating anti-TSHR autoantibodies and contribute to lacrimal gland impairment [46]. This is an immune-mediated lacrimal gland dysfunction initially characterized by inflammation and followed by gland fibrosis and dropout, manifesting as a secondary Sjögren's syndrome in long-lasting disease [46-50]. Proteomics of tear fluids demonstrated an upregulation of inflammatory proteins and a downregulation of protective proteins in GO, with a significantly different panel compared to dryeye patients and controls [51]. Elevated tear osmolarity is the main component of dry eye in GO, leading to symptomatic ocular surface disease that significantly affects QoL $[52,53]$.

For every form of dry eye, baseline treatment consists of nonpreserved artificial tears containing a demulcent with long retention time, such as sodium hyaluronate, applied several times per day, as required, to protect the ocular surface and control symptoms from the early stages of the disease [54]. Osmoprotective agents offer additional epithelial protection and symptomatic control especially in cases with increased osmolarity as in GO [55, 56]. 


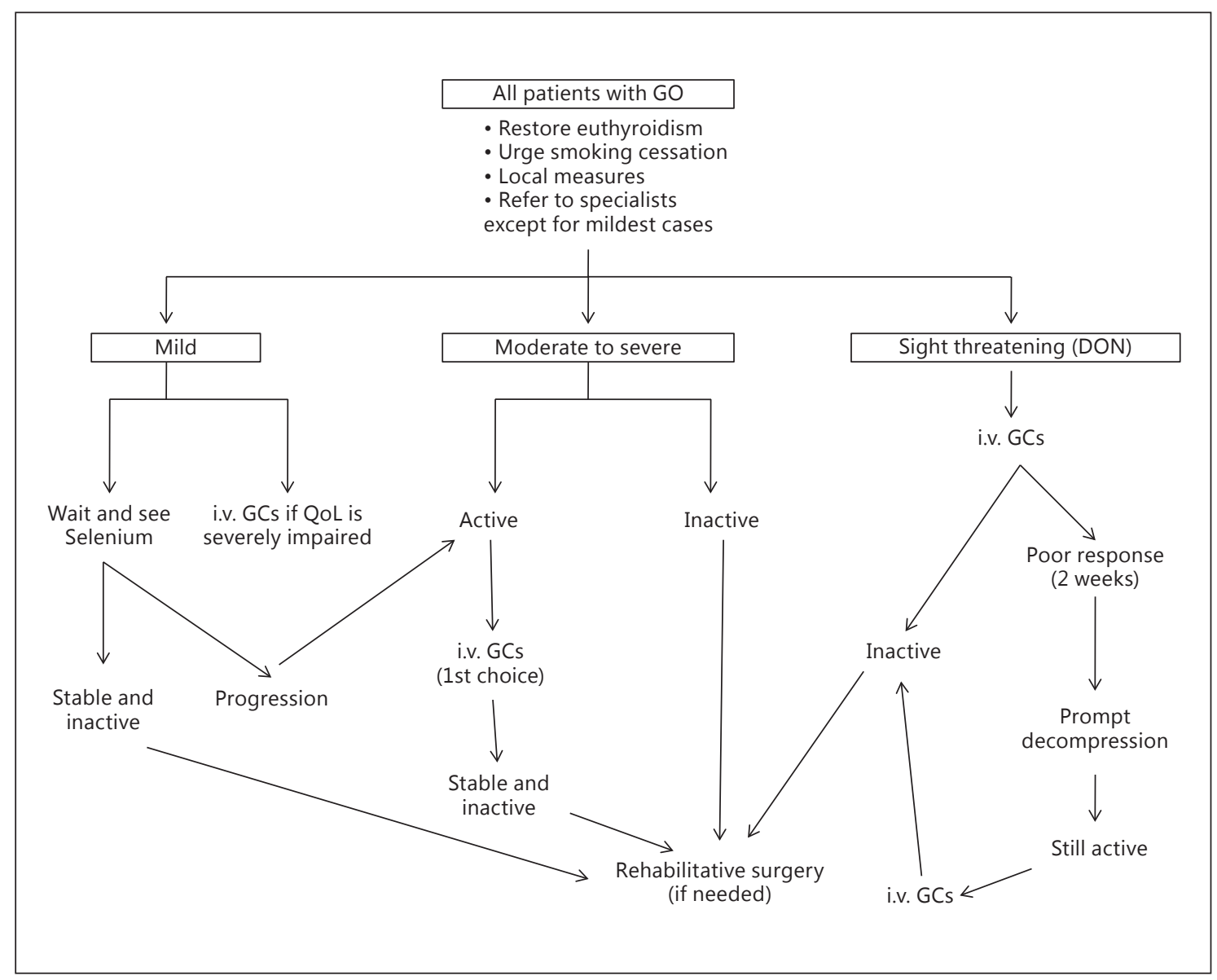

Fig. 1. Management of GO. For definition of activity and severity, see text and table 2, for local measures, see text.

\section{Recommendation}

7 We recommend that all patients with GO be evaluated for ocular surface disease and treated extensively with nonpreserved artificial tears with osmoprotective properties at all times in the course of their disease unless corneal exposure requires the higher protection that gels or ointment can offer especially at nighttime. $(1, \varnothing \varnothing \bigcirc \bigcirc)$

\section{How Should Mild GO Be Managed?}

In most patients with mild GO, a watchful strategy is sufficient (fig. 1) [1,2]. Control of thyroid dysfunction, refraining from smoking and local measures (artificial tears or ointments) should be implemented. Occasionally, objectively mild GO has a profound impact on QoL: these cases may be considered as moderate-to-severe GO and offered immunosuppressive treatment or rehabilitative surgery (see the following two sections) $[1,2]$.
Selenium is incorporated as selenocysteine into several selenoproteins, which have a major role in the maintenance of the cellular redox state $[57,58]$. In vivo and in vitro studies have shown that increased generation of reactive oxygen species may be involved in the pathogenesis of GO [59]. The effect of selenium supplementation on the course of mild GO was evaluated in a large, multicenter, randomized, double-blind, placebo-controlled trial [60]. Patients were randomly assigned to 6 months of treatment with sodium selenite $(100 \mu \mathrm{g}$ twice daily, corresponding to $93.6 \mu \mathrm{g}$ of elemental selenium/day) or placebo. The primary outcomes were changes in the QoL and overall ocular involvement at 6 months. Both improved significantly in the selenium group compared to the placebo group (overall ocular improvement: 61 vs. $36 \%$ in the placebo group, $\mathrm{p}<0.001$ ), and improvement was maintained at 12 months, after selenium withdrawal; in addition, the rate of progression of GO to more severe 
forms after intervention was significantly lower in the selenium group ( 7 vs. $26 \%$ in the placebo group, p < $0.001)[60]$. No selenium-related adverse events were observed. Enrolled patients mostly came from marginally selenium-deficient areas in Europe [61]. Whether selenium supplementation is beneficial and safe also for patients with mild GO residing in selenium-sufficient areas is unclear. In long-standing, inactive, mild GO, there is no evidence that selenium is effective. In these cases, rehabilitative surgery can be performed, as needed $[1,2]$ (fig. 1).

\section{Recommendations}

8 We recommend that mild GO be treated with local treatments and general measures to control risk factors; if the impact of the disease on QoL outweighs risks, then immunosuppressive therapy (for active $\mathrm{GO}$ ) or rehabilitative surgery (for inactive GO) may be justified.

$(1, \varnothing \varnothing \varnothing \bigcirc)$

9 We recommend that a 6-month selenium supplementation be given to patients with mild GO of relatively short duration, because it improves eye manifestations and QoL and prevents GO progression to more severe forms.

$(1, \varnothing \varnothing \varnothing \bigcirc)$

\section{How Should Moderate-to-Severe and Active GO Be Managed?}

First-Line Treatment

High-dose systemic glucocorticoids (GCs) are currently the first-line treatment for moderate-to-severe and active GO (fig. 1) [1, 2, 62]. Proof of principle of the efficacy of intravenous GCs was provided by a small randomized clinical trial [favorable outcome in 5 of 6 (83\%) GC-treated patients vs. 1 of 9 (11\%) placebotreated patients] [63]. Intravenously administered GCs are more effective and better tolerated than oral GCs (rate of adverse events: 39 vs. $81 \%$, p < 0.001) [1, 2, 6466]. Several randomized clinical trials found a response rate of approximately $70-80 \%$ in patients treated intravenously compared to $50 \%$ in those treated orally [62, 64]. Therefore, GCs are preferentially administered intravenously for the treatment of moderate-to-severe and active GO $[65,66]$. Intravenous GCs exert their immunosuppressive effect via both nongenomic (quick effect, within minutes) and genomic (long-term effect) pathways [67].

The most common schedule for intravenous GC therapy, based on a randomized clinical trial [68], is a cumulative dose of $4.5 \mathrm{~g}$ of methylprednisolone, divided into 12 weekly infusions ( 6 weekly infusions of $0.5 \mathrm{~g}$, followed by 6 weekly infusions of $0.25 \mathrm{~g}$ ) [68]. In a recent randomized study, this schedule was compared with a shorter regimen of the same cumulative dose (daily infusion of $0.5 \mathrm{~g}$ for 3 days over 2 weeks, followed by a daily infusion of $0.25 \mathrm{~g}$ for 3 days over 2 weeks) [69]. The latter protocol was, however, associated with lower efficacy compared to the standard protocol (response rate of 41 vs. $77 \%$; $=0.0025$ ) and toxicity was higher [69]. In a large, multicenter EUGOGO randomized clinical trial of 159 patients with moderate-to-severe and active GO, three different cumulative doses of methylprednisolone were used (7.47, 4.98 and $2.25 \mathrm{~g}$ ) over the same time period [70]. CAS decreased significantly with all doses, but the overall ophthalmic improvement was significantly more common using the highest dose (52 vs. 35 and $28 \%$ using the other two doses, respectively) [70]. However, the highest dose was associated with a slightly greater frequency of adverse events. The authors concluded that a cumulative dose of $4.5-5 \mathrm{~g}$ could be used in most cases, while the highest dose should be reserved to more severe cases [70]. High daily doses (0.5-1.0 g) administered several times per week for 2 consecutive weeks are usually necessary in patients with sight-threatening GO [71], but high single $(>0.5 \mathrm{~g})$ and/or cumulative doses ( $>8 \mathrm{~g}$ ) of intravenous GCs are associated with a 2 -fold higher rate of adverse events ( 56 vs. $28 \%, \mathrm{p}<0.001$, and 52 vs. $33 \%, \mathrm{p}=0.034$, respectively) [72], including serious cardiovascular, cerebrovascular and hepatic toxicity $[62,64]$. A recent review of 14 studies including 1,045 GO patients determined the morbidity and mortality of intravenous GC therapy to be 6.5 and $0.6 \%$, respectively [62]. Safety data suggest that single doses should not exceed $0.75 \mathrm{~g}$ [73], cumulative doses should be less than $8.0 \mathrm{~g}$, and consecutive-day therapy should be avoided [62]. Assessment of liver enzymes, viral markers for hepatitis, fasting serum glucose levels and hepatic ultrasound is advised prior to GC therapy $[62,65,73]$. Contraindications to therapy include evidence of recent viral hepatitis, significant hepatic dysfunction, severe cardiovascular morbidity, uncontrolled hypertension, psychiatric disorders and inadequately controlled diabetes $[62,69]$. Liver enzymes, glucose levels and blood pressure are best monitored monthly during treatment. Proton pump inhibitors to prevent peptic ulcer are recommended, and bone protection may be required, especially in patients with multiple risk factors for osteoporosis. 
Fig. 2. First-line therapeutic approach in patients with moderate-to-severe and active GO and options in the case of an absent or incomplete response to treatment. $\mathrm{Rx}=$ Radiotherapy.

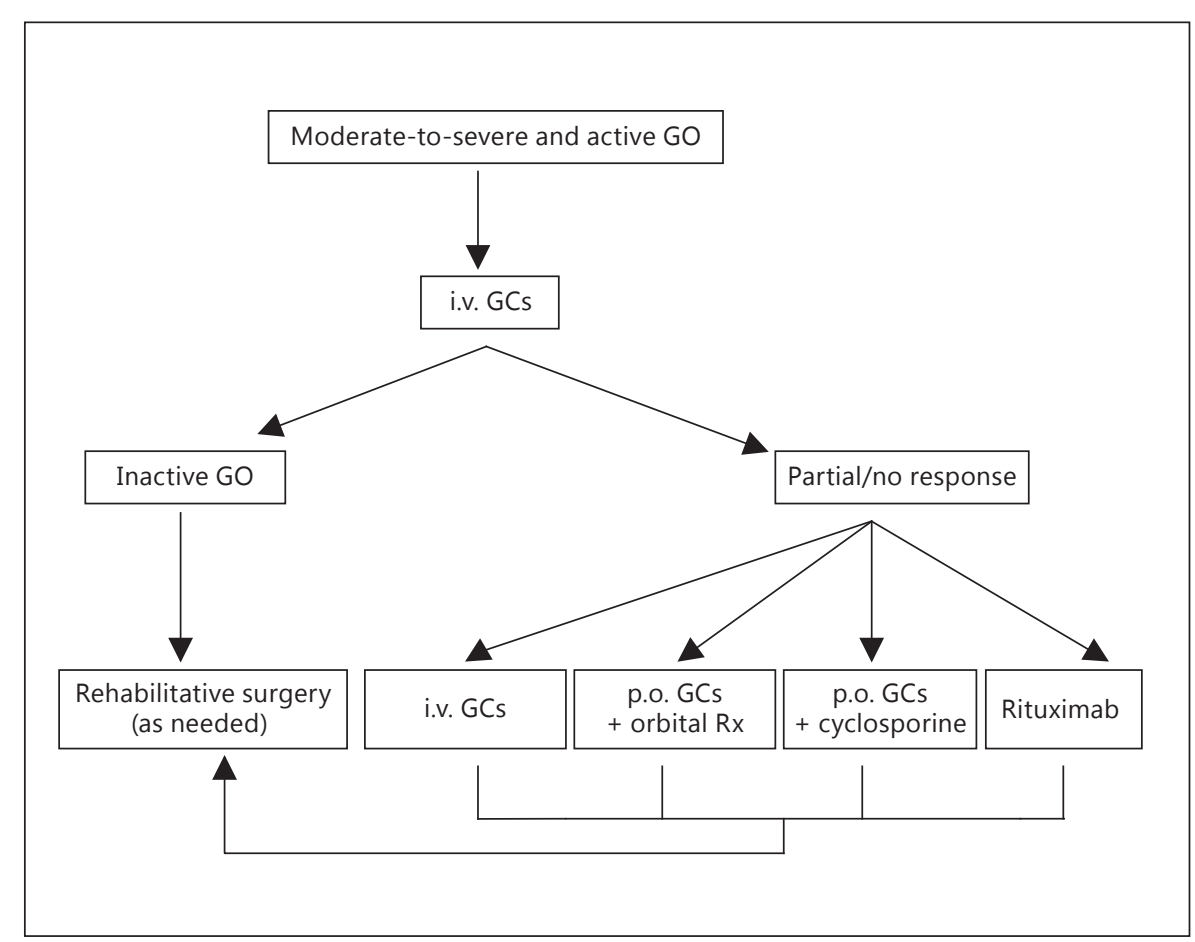

\section{Recommendations}

$10 \mathrm{We}$ recommend that high-dose intravenous GCs be considered as first-line treatment for moderate-to-severe and active GO. Intravenous GC therapy should be performed in experienced centers that can safely manage potentially serious adverse events.

$(1, \varnothing \varnothing \varnothing \varnothing)$

11 We recommend that the cumulative dose of intravenous GCs should not exceed $8.0 \mathrm{~g}$ and that GO patients with evidence of recent viral hepatitis, significant hepatic dysfunction, severe cardiovascular morbidity or psychiatric disorders should not be administered intravenous GCs; diabetes and hypertension should be well controlled before starting treatment.

$(1, \varnothing \varnothing \bigcirc \bigcirc)$

$12 \mathrm{We}$ recommend an intermediate-dose schedule of methylprednisolone, i.e. a starting dose of $0.5 \mathrm{~g}$ once weekly for 6 weeks, followed by $0.25 \mathrm{~g}$ once weekly for 6 weeks ( $4.5 \mathrm{~g}$ cumulative dose) in most cases of moderate-to-severe and active GO. High-dose regimens, i.e. a starting dose of $0.75 \mathrm{~g}$ once weekly for 6 weeks, followed by $0.5 \mathrm{~g}$ once weekly for 6 weeks ( $7.5 \mathrm{~g}$ cumulative dose) should be reserved for the worst cases within the moderate-to-severe spectrum.

$$
(1, \varnothing \varnothing \varnothing \varnothing)
$$

What Are the Indications for Withdrawing GCs?

Some patients respond early to intravenous GCs, while others take longer. Anecdotal experience suggests that early (within 2 weeks) response may be predictive of longterm response to GCs. Current evidence suggests that intravenous GC pulse should not continue for more than 12 weeks and the cumulative dose of methylprednisolone should not exceed $8 \mathrm{~g}$ (recommendations 11 and 12), thus defining broad boundaries for safe use of high-dose intravenous GC pulse therapy. However, adverse effects of GCs vary between individuals [73] and often occur with the recommended regimens. Maintaining a balance between benefit and harm is an important task for clinicians supervising GC therapy and may change during the course of treatment. When the balance tips against continuation of GCs, the options are to discontinue medical therapy or consider another form of treatment.

\section{Recommendation}

13 We suggest that clinicians should monitor each individual patient receiving GC therapy for response to treatment and adverse effects. When side effects outweigh benefits, clinicians should consider withdrawal of GC treatment in favor of another modality or watchful monitoring. $(2, \varnothing \varnothing \bigcirc \bigcirc)$ 
Second-Line Treatments

Although intravenous GCs are the first-line and generally effective treatment for moderate-to-severe and active GO, partial or inadequate responses or recurrences are not uncommon [70]. Management of patients experiencing medical treatment failure to intravenous GCs is a major challenge [74] due to the limited evidence about the efficacy of alternative treatment regimens in this clinical setting. This may be further complicated if patients do not wish to recommence GC or when they have experienced troublesome side effects of GC therapy.

Several options can be planned if GO is still active:

(a) A second course of intravenous GCs can be administered if the patient tolerates it and a cumulative dose of $8 \mathrm{~g}$ of methylprednisolone is not exceeded (fig. 2) [1, 2, $70,72]$.

(b) Orbital radiotherapy has been shown in randomized clinical trials to be more effective than sham irradiation in improving diplopia and range of ductions $[75,76]$. One randomized clinical trial has questioned its efficacy [77]. In another randomized clinical trial, orbital radiotherapy was shown to be as effective as oral GCs [78]. Orbital radiotherapy has been shown in randomized clinical trials to synergistically potentiate the effects of oral GCs $[79,80]$. It is possible that orbital radiotherapy may also potentiate the effects of intravenous GCs, but evidence on this specific issue is currently missing [81]. A cumulative dose of 20 Gy per orbit fractionated in 10 daily doses given over a 2-week period is commonly used $[1,2]$, but an alternative regimen of 1 Gy per week over a 20 -week period was shown to be equally effective and better tolerated $[82,83]$. Mild and transient exacerbation of ocular symptoms induced by irradiation may occur, but can be controlled by concomitant low-dose oral GC administration [81]. Data on long-term safety are reassuring [8486].

(c) Two randomized controlled studies have demonstrated that the combination of cyclosporine with oral GCs was more effective than either treatment alone in patients with moderate-to-severe and active GO $[87,88]$. In one study, two groups of patients were treated with oral prednisone (starting dose, $100 \mathrm{mg}$ per day) in decreasing doses for 3 months, alone or in combination with cyclosporine (starting dose, $5 \mathrm{mg} / \mathrm{kg}$ body weight), which was then continued up to 12 months [87]. Combined treatment was associated with a better ocular outcome and a significantly lower rate of recurrences of GO [87]. In the second study, patients who did not respond adequately to single-drug therapy, either prednisone (starting dose, 60 $\mathrm{mg}$ per day) or cyclosporine (starting dose, $7.5 \mathrm{mg} / \mathrm{kg}$ body weight), received also the second drug: about $60 \%$ of nonresponders to single-drug therapy had a response to combined-drug therapy [88]. The most common adverse events related to cyclosporine are dose-dependent liver and renal toxicities, and gingival hyperplasia. In one study on the use of cyclosporine for GO, a mild, nonsignificant increase in serum creatinine levels was noted in all patients, and 1 case of Klebsiella pneumoniae infection was observed in the cyclosporine group [87]. In the other study, 1 patient had an irreversible rise in the plasma creatinine concentration, and 6 patients had a transient rise in blood pressure [88].

(d) Rituximab has been used off-label in autoimmune disorders because of its direct B-cell-depleting action and modulation of all B-cell functions $[89,90]$. In earlier noncontrolled reports $[91,92]$, rituximab was employed in patients with active GO unresponsive to intravenous GCs, and in a small open study [93] it was given as a firstline treatment, with disease inactivation as the end point. The results of two small-sized randomized clinical trials of rituximab in moderate-to-severe and active GO from single centers have recently been published. In one study of 31 patients treated with rituximab $(n=15)$ or intravenous GCs $(\mathrm{n}=16)$, GO was more significantly inactivated after rituximab (100 vs. $69 \%$ after intravenous GCs); disease reactivation never occurred after rituximab, although it did in $31 \%$ of patients after intravenous GCs [94]. Rituximab was slightly more effective than intravenous GCs on ocular motility and QoL [94]. Rituximab was given at a dose of $1,000 \mathrm{mg}$ (administered twice over 2 weeks) in the first 5 patients, and $500 \mathrm{mg}$ as a single injection in the remaining 10 patients, based on the observation of a complete B-cell depletion after only $100 \mathrm{mg}$ of rituximab [95]. In the second study, rituximab (1,000 mg twice over 2 weeks) was given to 13 patients and compared to placebo $(\mathrm{n}=12)$ [96]. This study failed to demonstrate a difference in outcomes between rituximab and placebo [96]. Two patients, who had no overt or impending dysthyroid optic neuropathy (DON) prior to treatment, developed DON after rituximab. The reasons for the divergent outcomes in the two studies remain elusive. A major difference that may have negatively influenced the outcome of the latter compared to the former study is a longer disease duration. In view of these conflicting results, larger multicenter studies are warranted to establish whether rituximab could be considered a first-line treatment for moderate-to-severe and active GO, as an alternative to high-dose GCs. However, the results of one out of two randomized clinical trials and few nonrandomized studies suggest that rituximab 
could be considered as a second-line therapeutic option after failure of intravenous GC treatment. Rituximab has been employed successfully in 10 patients with DON [97-99], but the available evidence from one of the randomized studies [96], as well as a case report of a patient with GC-resistant GO [100], suggests that progression of DON may also occur after rituximab. Based on the above, rituximab should not be used in patients with impending DON or long duration of disease. Infusion-related reactions are the most frequently reported short-term side effects of rituximab [101], may occur in about $10-30 \%$ of patients at first infusion and can be minimized by premedication with antihistamine and $100 \mathrm{mg}$ of hydrocortisone prior to infusion. Rarely, transient, but significant periorbital edema and inflammation may occur. A recent review of over 3,000 patients with rheumatoid arthritis showed comparable serious infection rates in those treated with rituximab versus placebo plus methotrexate over 9.5 years of observation [102]. Progressive multifocal leukoencephalopathy has been reported in patients receiving rituximab associated with other immunosuppressants, mostly in patients with systemic lupus erythematosus [103].

(e) Watchful monitoring may be indicated in some patients after GC withdrawal, because ocular findings of orbital vascular congestion can show similarities with active GO, such as eyelid edema, eyelid and conjunctival redness, and chemosis more frequently in patients with longer disease duration. Thus, patients with high CAS poorly responsive to immunosuppressive treatment and relatively long-lasting disease should be evaluated for orbital vascular congestion, because orbital decompression can improve clinical features by increasing the venous outflow of the orbit [16].

All of the above options are worth considering in view of the current limited evidence. Shared decision-making is an appropriate way of selecting the most suitable option, because it balances benefits against potential side effects of each option in the context of the individual patient and considers the patient's comorbidities, personal circumstances and values, and impact of the disease on QoL [104].

\section{Recommendation}

14 We recommend shared decision-making as an appropriate approach to select a second-line therapy in patients with moderate-to-severe and active GO.

$(1, \varnothing \varnothing \bigcirc \bigcirc)$

\section{Other Treatments}

Periocular injections of triamcinolone acetate $(40 \mathrm{mg} /$ $\mathrm{ml}$ ) were shown to reduce diplopia and extraocular muscle size in recent-onset and active GO by two randomized clinical trials, with no serious local or systemic adverse effects $[105,106]$. Subconjunctival triamcinolone injections were effective in resolving eyelid swelling and mild degrees of retraction in recent-onset GO, the only side effect being a transient elevation in intraocular pressure [107].

Treatment with other drugs, including azathioprine [108], ciamexone [109] and somatostatin analogues [110113], has marginal or unproven beneficial effects on GO. Their use cannot be recommended for moderate-to-severe and active GO. Intravenous immunoglobulins were found to be comparably effective to high doses of oral GCs in one randomized and in one prospective controlled trial $[114,115]$; however, the high costs and, at that time, putative viral (hepatitis and HIV) transfer markedly limited the widespread use of this cumbersome treatment.

In active disease with possibly variable (small to moderate: usually $<15$ prismatic diopters) squint angle, prismatic lenses can be of help in restoring fusion in the case of primary gaze diplopia or compensatory torticollis. Botulinum toxin can also be beneficial to treat upper-lid retraction and lagophthalmos. The use of botulinum introduces an additional variable that needs to be considered when following the patients [116].

\section{How Should Moderate-to-Severe and Inactive GO Be Managed?}

This condition can require different degrees of surgical rehabilitation. The type and extension of surgeries depends on the amount of disfigurement and/or functional impairment that persists in the postinflammatory phase of the disease. Decompression surgery, strabismus surgery, lid lengthening and cosmetic periorbital surgeries can be necessary and should be performed in the given order as the preceding step may influence the necessity or the extension of the step that follows [117].

\section{Decompression Surgery}

Different techniques of decompression [118], lid lengthening and cosmetic surgery can be applied depending on the severity of the orbitopathy, anatomical background, concomitant diseases, patient expectations and social/cultural background. No technique fits all. Minimally invasive approaches are preferred. Decompression surgery is aimed at reducing the raised intraorbital pressure which is responsible for the typical signs and symptoms of the disease. This is achieved by enlarging the bony 
orbit (different degrees of extension of medial/lateral orbital walls or removal of the orbital floor) or by means of different amounts of fat excision (usually from the inferolateral and inferomedial extraconal compartments). When decompression surgery is performed on patients affected with moderate-to-severe and inactive GO, expected beneficial effects include reduction in exophthalmos periorbital puffiness (swelling and fat prolapse) and lid retraction. Results are generally proportional to the extent of osteotomies or fat removal and are not influenced by the time elapsed between GO duration and decompression surgery [119] or by previous radiotherapy [120]. Other positive effects of decompression include a decrease in intraocular tension and relief of pain, improvement in preexisting strabismus/requirement for subsequent surgical correction and cure of postural visual obscuration in patients with orbital and optic nerve microvasculopathy. The most common complications are new onset or worsening of preexisting strabismus and globe dystopia [121].

\section{Squint Surgery}

Squint surgery aims firstly to restore fusion in primary position avoiding diplopia in down gaze and then to correct residual incomitances $[122,123]$. This is achieved by means of extension of extraocular rectus muscle recessions and retroequatorial myopexias. Extraocular muscle recessions often need to be generous, thus tendons elongations and simultaneous conjunctiva recession are mandatory for maintaining the contact arch and avoiding loss of effectiveness of recession surgery. Rarely, oblique muscles need to be operated. Topical anesthesia can be used; general anesthesia is to be considered when more muscles need to be operated or when correcting residual incomitances [121].

\section{Eyelid Surgery}

In $\mathrm{GO}$, upper- and lower-lid retraction are due to a combination of inflammation, fibrosis, adrenergic stimulation and restriction of vertical rectus muscles. Exophthalmos also contributes to increasing eyelid aperture by displacing either the upper or the lower lid. Correction of upper- or lower-lid retraction implies recession of the lid retractors. Spacers are not essential for upper-lid lengthening procedures, but are necessary to provide height and the necessary stiffness to support the lower lid against gravity when severely retracted. A number of autologous, homologous, xenogenic and synthetic materials have been used, including ethanol-preserved donor sclera, upper-lid tarsus, cartilage grafts, porous polyethylene, polytetrafluoroethylene or polyester meshes. Autogenous hard-palate mucosal grafts are relatively easy to obtain, are similar to lower-lid tarsus in terms of contour, thickness and stiffness, have a mucosal surface, have no risk of rejection and undergo minimal shrinkage following grafting. Ophthalmic complications of hard-palate mucosal grafting are uncommon and morbidity at the donor site rare. Hard-palate mucosal grafts providing structural and epithelial elements are a suitable material for posterior lamella augmentation in lower-lid lengthening. Homologous acellular dermal matrix with an appropriate consistency for posterior lamella augmentation is an optimal alternative to hard-palate mucosa, but unfortunately it is not easily available throughout Europe.

Treatment of persistent upper-eyelid retraction is surgical and by far less predictable than that of the lower lid. Medical therapy with $a$-blocker eye drops or with postganglial adrenergic blocker drugs is not very effective or limited by side effects. Botulinum toxin is an effective option, but its effect is transient, and repeated injections are necessary. Temporary undercorrection or overcorrection can occur, and thus impaired elevation and paralysis of the orbicularis muscle (which are highly undesirable complications in GO patients in view of the risk for corneal exposure). Upper-eyelid lengthening is one of the last stages of the long-lasting and somewhat exhausting surgical rehabilitation of patients with GO. Although several surgical techniques are currently in use, the optimal approach is difficult to define. The simplest and less timeconsuming technique is worth considering first. Sutureless Müllerectomy, transconjunctival free en block recession of the levator palpebrae superioris muscle and conjunctiva, or transcutaneous blepharotomy fulfill such a criterion and can be used systematically for mild-to-moderate or for moderate-to-severe degrees of upper-lid retraction $[121,124]$. Cosmetic periorbital surgery in GO is not substantially different than that used for the aging face. Sculpturing or excision of the sub brow fat pad can benefit from the use of a $\mathrm{CO}_{2}$ laser [124].

\section{Recommendation}

15 We recommend that elective rehabilitative surgery be offered to patients with $\mathrm{GO}$ when the disease is associated with a significant impact on visual function or QoL after the disease has been inactive for at least 6 months. If more than one surgical procedure is required, orbital decompression should precede squint surgery and be followed by lid surgery. Patients should be referred to specialized centers and specialized surgeons able to tailor different possible surgeries to the specific need of the individual patient.

\section{$(1, \varnothing \varnothing \bigcirc \bigcirc)$}


How Should Sight-Threatening GO Be Managed?

Sight-threatening GO due to DON and/or severe corneal exposure (large epithelial and/or stromal defects) or corneal breakdown (descemetocele or frank perforation) is an emergency that should be treated immediately. Eyeball subluxation should be regarded as a potential cause of optic nerve stretching (DON) and/or corneal breakdown. Recent development of choroidal folds (caused by indentation of the eyeball by enlarged extraocular muscles) can become a permanent cause of metamorphopsia if not treated urgently.

Very high doses of intravenous GCs (e.g. 500-1,000 mg of methylprednisolone for 3 consecutive days or on alternate days during the 1st week) are usually the firstline treatment for DON $[71,125]$. This course can be repeated after a week and is effective in approximately $40 \%$ of patients with recovery of normal or near-normal vision $[71,125]$. If the response is absent or poor, or when there is rapid deterioration in visual function (acuity/visual field), urgent decompression surgery should be performed. In the case of optic nerve compression, apex decompression can be better achieved by means of medial orbital wall removal; however, several studies have shown that targeting other orbital bony or fat territories is equally effective in restoring optic nerve function.

Any form of decompression surgery aimed at substantial reduction of intraorbital pressure and exophthalmos is the treatment of choice for DON because of optic nerve stretching and eyeball subluxation. Additionally, it can be beneficial for choroidal folds and severe corneal exposure when lubricants, moisturized chamber, blepharorrhaphy, tarsorraphy, lid lengthening and/or extraocular muscle recession fail to protect the cornea. Gluing or transplantation may be necessary when there is corneal breakdown.

\section{Recommendations}

$16 \mathrm{We}$ recommend that severe corneal exposure be treated medically or by means of progressively more invasive surgeries as soon as possible in order to avoid progression to corneal breakdown. The latter should be immediately addressed surgically.

$(1, \varnothing \varnothing \varnothing \bigcirc)$

17 We recommend that DON be treated immediately with very high doses of intravenous GCs (500-1,000 mg of methylprednisolone for 3 consecutive days or on alternate days during the 1st week), and urgent orbital decompression be performed if response is absent or poor within 2 weeks. Recent-onset choroidal folds and eyeball subluxation should undergo orbital decompression as soon as possible. If DON has resolved or improved after 2 weeks, pulses of weekly intravenous methylprednisolone should be continued as described for the management of moderate-to-severe and active GO.

$(1, \varnothing \varnothing \varnothing \bigcirc)$

\section{Perspectives and Conclusions}

Although GO is the most frequent extrathyroidal manifestation of Graves' disease, it is a rare disorder [126]. However, it has a large negative impact on QoL of affected individuals even when mild $[10,127,128]$. The Amsterdam declaration, signed by numerous international experts on GO, national and international professional organizations, national and international patient associations, established general objectives aimed at minimizing GO-associated morbidity, improving patients' QoL and preventing the occurrence of GO in at-risk individuals [129]. The recent observation that patients referred to tertiary centers have less severe and active GO [8] might indeed reflect an increased awareness of the disease and, consequently, an earlier diagnosis and management of Graves' hyperthyroidism and GO as well as a more effective use of preventive measures, including antismoking measures, use of antioxidants (selenium) in mild forms, better control and stricter follow-up of thyroid dysfunction. Our understanding of the pathogenesis of GO has improved [130-132], but treatments of severe forms of the disease are still imperfect, because they do not target precisely the pathogenic mechanisms of the disease [133]. Nevertheless, steady progress is being made in this field. Randomized clinical trials have been published, either defining optimization of old treatments, such as high-dose GCs, or proposing novel biological treatments, such as rituximab. Other ongoing studies are evaluating the efficacy (and safety) of immunosuppressants, such as mycophenolate, or biologics, such as tocilizumab [134] or anti-IGF-1 receptor monoclonal antibody. Recommendations about the role of these novel agents will have to await the results of large randomized controlled studies.

\section{Appendix}

Participants of the EUGOGO

Fotini Adamidou (Thessaloniki), Panagiotis Anagnostis (Thessaloniki), Goksun Ayvaz (Ankara), Claudio Azzolini (Varese), Antonella Boschi (Brussels), Claire Bournaud (Lyon), Lucy Clarke (Newcastle upon Tyne), Nicola Currò (Milan), Chantal Daumerie 
(Brussels), Colin Dayan (Cardiff), Dagmar Fuhrer (Essen), Onur Konuk (Ankara), Michele Marinò (Pisa), Daniel Morris (Cardiff), Marco Nardi (Pisa), Simon Pearce (Newcastle upon Tyne), Susanne Pitz (Mainz), Gottfried Rudovsky (Olten), Guia Vannucchi (Milan), Christine Vardanian (Lyon) and Georg von Arx (Olten).

\section{Disclosure Statement}

No conflict of interest to declare.

\section{References}

1 Bartalena L, Baldeschi L, Dickinson AJ, Eckstein A, Kendall-Taylor P, Marcocci C, Mourits MP, Perros P, Boboridis K, Boschi A, Curro N, Daumerie C, Kahaly GJ, Krassas GE, Lane CM, Lazarus JH, Marino M, Nardi M, Neoh C, Orgiazzi J, Pearce S, Pinchera A, Pitz S, Salvi M, Sivelli P, Stahl M, von Arx G, Wiersinga WM; European Group on Graves' Orbitopathy (EUGOGO): Consensus statement of the European Group on Graves' Orbitopathy (EUGOGO) on management of GO. Eur J Endocrinol 2008;158:273-285.

2 Bartalena L, Baldeschi L, Dickinson AJ, Eckstein A, Kendall-Taylor P, Marcocci C, Mourits MP, Perros P, Boboridis K, Boschi A, Curro N, Daumerie C, Kahaly GJ, Krassas G, Lane CM, Lazarus JH, Marino M, Nardi M, Neoh C, Orgiazzi J, Pearce S, Pinchera A, Pitz S, Salvi M, Sivelli P, Stahl M, von Arx G, Wiersinga WM: Consensus statement of the European Group on Graves' Orbitopathy (EUGOGO) on management of Graves' orbitopathy. Thyroid 2008; 18:333-346.

-3 Bahn R: The EUGOGO consensus statement on the management of Graves' orbitopathy: equally applicable to North American clinicians and patients. Thyroid 2008;18:281-282.

4 Bahn RS, Burch HB, Cooper DS, Garber JR, Greenlee MC, Klein I, Laurberg P, McDougall IR, Montori VM, Rivkees SA, Ross DS, Sosa JA, Stan MN: Hyperthyroidism and other causes of thyrotoxicosis: management guidelines of the American Thyroid Association and American Association of Clinical Endocrinologists. Endocr Pract 2011;17:456-520.

5 Abraham-Nordling M, Bystrom K, Torring O, Lantz M, Berg G, Calissendorff J, Nystrom HF, Jansson S, Jorneskog G, Karlsson FA, Nystrom E, Ohrling H, Orn T, Hallengren B, Wallin G: Incidence of hyperthyroidism in Sweden. Eur J Endocrinol 2011;165:899-905.

6 Laurberg P, Berman DC, Bulow Pedersen I, Andersen S, Carle A: Incidence and clinical presentation of moderate to severe Graves' orbitopathy in a Danish population before and after iodine fortification of salt. J Clin Endocrinol Metab 2012;97:2325-2332.

7 Tanda ML, Piantanida E, Liparulo L, Veronesi G, Lai A, Sassi L, Pariani N, Gallo D, Azzolini C, Ferrario M, Bartalena L: Prevalence and natural history of Graves' orbitopathy in a large series of patients with newly diagnosed Graves' hyperthyroidism seen at a single center. J Clin Endocrinol Metab 2013;98:14431449.
8 Perros P, Zarkovic M, Azzolini C, Ayvaz G, Baldeschi L, Bartalena L, Boschi A, Bournaud C, Brix TH, Covelli D, Ciric S, Daumerie C, Eckstein A, Fichter N, Fuhrer D, Hegedus L, Kahaly GJ, Konuk O, Lareida J, Lazarus J, Leo M, Mathiopoulou L, Menconi F, Morris D, Okosieme O, Orgiazzi J, Pitz S, Salvi M, Vardanian-Vartin C, Wiersinga W, Bernard M, Clarke L, Curro N, Dayan C, Dickinson J, Knezevic M, Lane C, Marcocci C, Marino M, Moller L, Nardi M, Neoh C, Pearce S, von Arx G, Toruner FB: PREGO (presentation of Graves' orbitopathy) study: changes in referral patterns to European Group On Graves' Orbitopathy (EUGOGO) centres over the period from 2000 to 2012. Br J Ophthalmol 2015;99:1531-1535.

-9 Swiglo BA, Murad MH, Schunemann HJ, Kunz R, Vigersky RA, Guyatt GH, Montori VM: A case for clarity, consistency, and helpfulness: state-of-the-art clinical practice guidelines in endocrinology using the grading of recommendations, assessment, development, and evaluation system. J Clin Endocrinol Metab 2008;93:666-673.

10 Kahaly GJ, Petrak F, Hardt J, Pitz S, Egle UT: Psychosocial morbidity of Graves' orbitopathy. Clin Endocrinol (Oxf) 2005;63:395-402.

11 Terwee CB, Dekker FW, Mourits MP, Gerding MN, Baldeschi L, Kalmann R, Prummel MF, Wiersinga WM: Interpretation and validity of changes in scores on the Graves' ophthalmopathy quality of life questionnaire (GO-QOL) after different treatments. Clin Endocrinol (Oxf) 2005;54:391-398.

12 Ponto KA, Merkesdal S, Hommel G, Pitz S, Pfeiffer N, Kahaly GJ: Public health relevance of Graves' orbitopathy. J Clin Endocrinol Metab 2013;98:145-152.

13 Mourits MP, Prummel MF, Wiersinga WM, Koornneef L: Clinical activity score as a guide in the management of patients with Graves' ophthalmopathy. Clin Endocrinol (Oxf) 1997;47:9-14.

14 Piantanida E, Tanda ML, Lai A, Sassi L, Bartalena L: Prevalence and natural history of Graves' orbitopathy in the XXI century. J Endocrinol Invest 2013;36:444-449.

15 Perros P, Dayan CM, Ezra D, Estcourt S, Kickey J, Lazarus JH, MacEwen CJ, McLaren J, Rose GE, Uddin J, Vaidya B: Management of patients with Graves' orbitopathy: initial assessment, management outside specilised centres and referral pathways. Clin Med 2015; 151:173-178.
16 Onaran Z, Konuk O, Oktar SO, Yucel C, Unal M: Intraocular pressure lowering effect of orbital decompression is related to increased venous outflow in Graves' orbitopathy. Curr Eye Res 2014;39:666-672.

17 Estcourt S, Hickey J, Perros P, Dayan C, Vaidya $B$ : The patient experience of services for thyroid eye disease in the United Kingdom: results of a nationwide survey. Eur J Endocrinol 2009;161:483-487.

18 Wiersinga WM: Smoking and thyroid. Clin Endocrinol (Oxf) 2013;79:145-151.

19 Bartalena L, Martino E, Marcocci C, Bogazzi F, Panicucci M, Velluzzi F, Loviselli A, Pinchera A: More on smoking habits and Graves' ophthalmopathy. J Endocrinol Invest 1989; 12:733-737.

20 Prummel MF, Wiersinga WM: Smoking and risk of Graves' disease. JAMA 1993;269:479482.

21 Bartalena L, Marcocci C, Bogazzi F, Manetti L, Tanda ML, Dell'Unto E, Bruno-Bossio G, Nardi M, Bartolomei MP, Lepri A, Rossi G, Martino E, Pinchera A: Relation between therapy for hyperthyroidism and the course of Graves' ophthalmopathy. N Engl J Med 1998;338:73-78.

22 Traisk F, Tallstedt L, Abraham-Nordling M, Andersson T, Berg G, Calissendorff J, Hallengren B, Hedner P, Lantz M, Nystrom E, Ponjavic V, Taube A, Torring O, Wallin G, Asman P, Lundell G: Thyroid-associated ophthalmopathy after treatment for Graves' hyperthyroidism with antithyroid drugs or iodine-131. J Clin Endocrinol Metab 2009;94: 3700-3707.

23 Bartalena L, Marcocci C, Tanda ML, Manetti L, Dell'Unto E, Bartolomei MP, Nardi M, Martino E, Pinchera A: Cigarette smoking and treatment outcomes in Graves ophthalmopathy. Ann Intern Med 1998;129:632635.

24 Eckstein A, Quadbeck B, Mueller G, Rettenmeier AW, Hoermann R, Mann K, Steuhl P, Esser J: Impact of smoking on the response to treatment of thyroid associated ophthalmopathy. Br J Ophthalmol 2003;87:773-776.

25 Pfeilschifter J, Ziegler R: Smoking and endocrine ophthalmopathy: impact of smoking severity and current vs lifetime cigarette consumption. Clin Endocrinol (Oxf) 1996;45: 477-481. 
26 Karlsson FA, Dahlberg PA, Jansson R, Westermark K, Enoksson P: Importance of TSH receptor activation in the development of severe endocrine ophthalmopathy. Acta Endocrinol (Copenh) 1989;121(suppl 2):132-141.

27 Prummel MF, Wiersinga W, Mourits M, Koornneef L, Berghout A, van der Gaag R: Amelioration of eye changes of Graves' ophthalmopathy by achieving euthyroidism. Acta Endocrinol (Copenh) 1989;121(suppl 2):185189.

28 Marcocci C, Bruno-Bossio G, Manetti L, Tanda ML, Miccoli P, Iacconi P, Bartolomei MP, Nardi M, Pinchera A, Bartalena L: The course of Graves' ophthalmopathy is not influenced by near total thyroidectomy: a case-control study. Clin Endocrinol (Oxf) 1999;51:503-508.

29 Acharya SH, Avenell A, Philip S, Burr J, Bevan JS, Abraham P: Radioiodine therapy (RAI) for Graves' disease (GD) and the effect on ophthalmopathy: a systematic review. Clin Endocrinol (Oxf) 2008;69:943-950.

- 30 Tallstedt L, Lundell G, Torring O, Wallin G, Ljunggren JG, Blomgren $H$, Taube A: Occurrence of ophthalmopathy after treatment for Graves' hyperthyroidism. The Thyroid Study Group. N Engl J Med 1992;326:1733-1738.

- 31 Vannucchi G, Campi I, Covelli D, Dazzi D, Curro N, Simonetta S, Ratiglia R, Beck-Peccoz P, Salvi M: Graves' orbitopathy activation after radioactive iodine therapy with and without steroid prophylaxis. J Clin Endocrinol Metab 2009;94:3381-3386.

-32 Lai A, Sassi L, Compri E, Marino F, Sivelli P, Piantanida E, Tanda ML, Bartalena L: Lower dose prednisone prevents radioiodine-associated exacerbation of initially mild or absent Graves' orbitopathy: a retrospective cohort study. J Clin Endocrinol Metab 2010;95: 1333-1337.

-33 Shiber S, Stiebel-Kalish H, Shimon I, Grossman A, Robenshtok E: Glucocorticoid regimens for prevention of Graves' ophthalmopathy progression following radioiodine treatment: systematic review and meta-analysis. Thyroid 2014;24:1515-1523.

- 34 Lazarus JH, Bartalena L, Marcocci C, Kahaly GJ, Krassas G, Wiersinga WM; EUGOGO (European Group on Graves' Orbitopathy): Glucocorticoid administration for Graves' hyperthyroidism treated by radioiodine. A questionnaire survey among members of the European Thyroid Association. J Endocrinol Invest 2010;33:409-413.

35 Watanabe N, Yoshimura NJ, Kozaki A, Iwaku K, Sekiya K, Kosuga Y, Matsumoto N, Suzuki M, Yoshihara A, Ohye H, Kobayashi S, Kunii Y, Mukasa K, Sugino K, Inoue T, Ito K: Radioiodine-associated exacerbation of Graves' orbitopathy in the Japanese population: randomized prospective study. J Clin Endocrinol Metab 2015;100:2700-2708.

-36 Tallstedt L, Lundell G, Blomgren H, Bring J Does early administration of thyroxine reduce the development of Graves' ophthalmopathy after radioiodine treatment? Eur J Endocrinol 1994;130:494-497.
37 Perros P, Kendall-Taylor P, Neoh C, Frewin S, Dickinson J: A prospective study of the effects of radioiodine therapy for hyperthyroidism in patients with minimally active Graves' ophthalmopathy. J Clin Endocrinol Metab 2005;90:5321-5323.

38 Bartalena L, Macchia PE, Marcocci C, Salvi M, Vermiglio F: Effects of treatment modalities for Graves' hyperthyroidism on Graves' orbitopathy: a 2015 Italian Society of Endocrinology Consensus Statement. J Endocrinol Invest 2015;38:481-487.

39 Gurdal C, Sarac O, Genc I, Kirimlioglu H, Takmaz T, Can I: Ocular surface and dry eye in Graves' disease. Curr Eye Res 2011;36:813.

40 Gupta A, Sadeghi PB, Akpek EK: Occult thyroid eye disease in patients presenting with dry eye symptoms. Am J Ophthalmol 2009; 147:919-923.

41 Bruscolini A, Abbouda A, Locuratolo N, Restivo L, Trimboli P, Romanelli F: Dry eye syndrome in non-exophthalmic Graves' disease. Semin Ophthalmol 2015;30:372-376.

42 Kocabeyoglu S, Mocan MC, Cevik Y, Irkec M: Ocular surface alterations and in vivo confocal microscopic features of corneas in patients with newly diagnosed Graves' disease. Cornea 2015;34:745-749.

43 Selter JH, Gire AI, Sikder S: The relationship between Graves' ophthalmopathy and dry eye syndrome. Clin Ophthalmol 2015;9:57-62.

44 Gilbard JP, Farris RL: Ocular surface drying and ocular tear film osmolarity in thyroid eye disease. Acta Ophthalmol (Copenh) 1983;61: 108-116.

45 Khumuran AK, Sunder S, Ahluwalia BK, Malhotra KC: Tear film profile in Graves' ophthalmopathy. Acta Ophthalmol (Copenh) 1992;70:346-349.

46 Eckstein AK, Finkenrath A, Heiligenhaus A, Renzing-Kohler K, Esser J, Krüger C, Quadbeck B, Steuhl KP, Gieseler RK: Dry eye syndrome in thyroid-associated ophthalmopathy: lacrimal expression of TSH receptor suggests involvement of TSHR-specific autoantibodies. Acta Ophthalmol Scand 2004;82: 291-297.

47 Ismailova DS, Fedorov AA, Grusha YO: Ocular surface changes in thyroid eye disease. Orbit 2013;32:87-90.

48 The definition and classification of dry eye disease: report of the Definition and Classification Subcommittee of the International Dry Eye WorkShop (2007). Ocul Surf 2007;5:7592.

49 Khalil HA, De Keizer RJ, Kijlstra A: Analysis of tear proteins in Graves' ophthalmopathy by high performance liquid chromatography Am J Ophthalmol 1988;106:186-190.

50 Khalil HA, De Keizer RJ, Bodelier VM, Kijlstra A: Secretory IgA and lysozyme in tears of patients with Graves' ophthalmopathy. Doc Ophthalmol 1989;72:329-334.
51 Matheis N, Grus FH, Breitenfeld M, Knych I, Funke S, Pitz S, Ponto KA, Pfeiffer N, Kahaly GJ: Proteomics differentiate between thyroidassociated orbitopathy and dry eye syndrome. Invest Ophthalmol Vis Sci 2015;56:26492656.

52 Iskeleli G, Karakoc Y, Abdula A: Tear film osmolarity in patients with thyroid ophthalmopathy. Jpn J Ophthalmol 2008;52:323326.

53 Yeatts RP: Quality of life in patients with Graves ophthalmopathy. Trans Am Ophthalmol Soc 2005; 103:368-411.

54 Vogel R, Crockett RS, Oden N, Laliberte TW, Molina L: Demonstration of efficacy in the treatment of dry eye disease with $0.18 \%$ sodium hyaluronate ophthalmic solution (Vismed, Rejena). Am J Ophthalmol 2010; 149:594-601.

55 Baudouin C, Aragona P, Messmer EM, Tomlinson A, Calonge M, Boboridis KG, Akova YA, Geerling G, Labetoulle M, Rolando M: Role of hyperosmolarity in the pathogenesis and management of dry eye disease: proceedings of the OCEAN group meeting. Ocul Surf 2013;11:246-258

-56 Baudouin C, Cochener B, Pisella PJ, Girard B, Pouliquen P, Cooper H, Creuzot-Garcher C: Randomized, phase III study comparing osmoprotective carboxymethylcellulose with sodium hyaluronate in dry eye disease. Eur J Ophthalmol 2012;22:751-761.

57 Rayman MP: Selenium and human health. Lancet 2012;379:1256-1268.

58 Kohrle J: Pathophysiological relevance of selenium. J Endocrinol Invest 2013;36(10 suppl):1-7.

59 Marcocci C, Bartalena L: Role of oxidative stress and selenium in Graves' hyperthyroidism and orbitopathy. J Endocrinol Invest 2013;36(10 suppl):15-20.

60 Marcocci C, Kahaly GJ, Krassas GE, Bartalena L, Prummel M, Stahl M, Altea MA, Nardi M, Pitz S, Boboridis K, Sivelli P, von Arx G, Mourits MP, Baldeschi L, Bencivelli W, Wiersinga W; European Group on Graves Orbithopathy: Selenium and the course of mild Graves' orbitopathy. N Engl J Med 2011;364:1920-1931.

61 Rayman MP: The importance of selenium to human health. Lancet 2000;356:233-241.

62 Zang S, Ponto KA, Kahaly GJ: Clinical review: intravenous glucocorticoids for Graves' orbitopathy: efficacy and morbidity. J Clin Endocrinol Metab 2011;96:320-332.

63 van Geest RJ, Sasim IV, Koppenschaar HPF, Kallman R, Stravers SN, Bijlsma WR, Mourits MP: Methylprednisolone pulse therapy for patients with moderately severe Graves' orbitopathy: a prospective, randomized, placebocontrolled study. Eur J Endocrinol 2006;158: 229-237.

64 Stiebel-Kalish H, Robenshtok E, Hasanreisoglu M, Ezrachi D, Shimon I, Leibovici L: Treatment modalities for Graves' ophthalmopathy: systematic review and metaanalysis. J Clin Endocrinol Metab 2009;94:27082716. 
-65 Marcocci C, Watt T, Altea MA, Rasmussen AK, Feldt-Rasmussen U, Orgiazzi J, Bartalena L: Fatal and non-fatal adverse events of glucocorticoid therapy for Graves' orbitopathy: a questionnaire survey among members of the European Thyroid Association. Eur J Endocrinol 2012;166:247-253.

-66 Bartalena L, Burch HB, Burman KD, Kahaly GJ: A 2013 European survey of clinical practice patterns in the management of Graves' disease. Clin Endocrinol (Oxf) 2016;84:115-120.

67 Zang S, Kahaly GJ: Steroids and the immune response in Graves' orbitopathy. Immunol Endocr Metab Agents Med Chem 2011;11: 90-98.

68 Kahaly GJ, Pitz S, Hommel G, Dittmar M: Randomized, single blind trial of intravenous versus oral steroid monotherapy in Graves' orbitopathy. J Clin Endocrinol Metab 2005; 90:5234-5240.

-69 Zhu W, Ye L, Shen L, Jiao Q, Huang F, Han R, Zhang X, Wang S, Wang W, Ning G: A prospective, randomized trial of intravenous glucocorticoids therapy with different protocols for patients with Graves' ophthalmopathy. J Clin Endocrinol Metab 2014;99:1999-2007.

-70 Bartalena L, Krassas GE, Wiersinga W, Marcocci C, Salvi M, Daumerie C, Bournaud C, Stahl M, Sassi L, Veronesi G, Azzolini C, Boboridis KG, Mourits MP, Soeters MR, Baldeschi L, Nardi M, Curro N, Boschi A, Bernard $M$, von Arx G: Efficacy and safety of three different cumulative doses of intravenous methylprednisolone for moderate to severe and active Graves' orbitopathy. J Clin Endocrinol Metab 2012;97:4454-4463.

-71 Currò N, Covelli D, Vannucchi G, Campi I, Pirola G, Simonetta S, Dazzi D, Guastella C, Pignataro L, Beck-Peccoz P, Ratiglia R, Salvi M: Therapeutic outcomes of high-dose intravenous steroids in the treatment of dysthyroid optic neuropathy. Thyroid 2014;24:897-905.

-72 Zang S, Ponto KA, Pitz S, Kahaly GJ: Dose of intravenous steroids and therapy outcome in Graves' orbitopathy. J Endocrinol Invest 2011;34:876-880

73 Riedl M, Kolbe E, Kampmann E, Kramer I, Kahaly GJ: Prospectively recorded and MedDRA-coded safety data of intravenous methylprednisolone therapy in Graves' orbitopathy. J Endocrinol Invest 2015;38:177-182.

74 Bartalena L: What to do for moderate-to-severe and active Graves' orbitopathy if glucocorticoids fail? Clin Endocrinol (Oxf) 2010; 73:149-152.

-75 Mourits MP, van Kempen-Harteveld ML, Garcia MB, Koppeschaar HP, Tick L, Terwee CB: Radiotherapy for Graves' orbitopathy: randomised placebo-controlled study. Lancet 2000;355:1505-1509.

-76 Prummel MF, Terwee CB, Gerding MN, Baldeschi L, Mourits MP, Blank L, Dekker FW, Wiersinga WM: A randomized controlled trial of orbital radiotherapy versus sham irradiation in patients with mild Graves' ophthalmopathy. J Clin Endocrinol Metab 2004;89: $15-20$.
77 Gorman CA, Garrity JA, Fatourechi V, Bahn RS, Petersen IA, Stafford SL, Earle JD, Forbes GS, Kline RW, Bergstralh EJ, Offord KP, Rademacher DM, Stanley NM, Bartley GB: A prospective, randomized, double-blind, placebo-controlled study of orbital radiotherapy for Graves' ophthalmopathy. Ophthalmology 2001;108:1523-1534.

78 Prummel MF, Mourits MP, Blank L, Berghout L, Koornneef L, Wiersinga WM: Randomized double-blind trial of prednisone versus radiotherapy in Graves' ophthalmopathy. Lancet 1993;342:949-954.

79 Marcocci C, Bartalena L, Bogazzi F, BrunoBossio G, Lepri A, Pinchera A: Orbital radiotherapy combined with high dose systemic glucocorticoids for Graves' ophthalmopathy is more effective than radiotherapy alone: results of a prospective randomized study. J Endocrinol Invest 1991;14:853-860.

-80 Bartalena L, Marcocci C, Chiovato L, Laddaga M, Lepri G, Andreani D, Cavallacci G, Baschieri L, Pinchera A: Orbital cobalt irradiation combined with systemic corticosteroids for Graves' ophthalmopathy: comparison with systemic corticosteroids alone. J Clin Endocrinol Metab 1983;56:1139-1144.

81 Tanda ML, Bartalena L: Efficacy and safety of orbital radiotherapy for Graves' orbitopathy. J Clin Endocrinol Metab 2012;97:3857-3865.

82 Kahaly GJ, Rosler HP, Pitz S, Hommel G: Low- versus high-dose radiotherapy for Graves' ophthalmopathy: a randomized, single blind trial, J Clin Endocrinol Metab 2000; 85:102-108.

83 Johnson KT, Wittig A, Loesch C, Esser J, Sauerwein W, Eckstein AK: A retrospective study on the efficacy of total absorbed orbital doses of 12,16 and 20 Gy combined with systemic steroid treatment in patients with Graves' orbitopathy. Graefes Arch Clin Exp Ophthalmol 2010;248:103-109.

84 Marcocci C, Bartalena L, Rocchi R, Marino M, Menconi F, Morabito E, Mazzi B, Mazzeo S, Sartini MS, Nardi M, Cartei F, Cionini L, Pinchera A: Long-term safety of orbital radiotherapy for Graves' ophthalmopathy. J Clin Endocrinol Metab 2003;88:3561-3566.

85 Marquez SD, Lum BL, McDougall IR, Katkuri S, Levin PS, MacManus M, Donaldson SS: Long-term results of irradiation for patients with progressive Graves' ophthalmopathy. Int J Radiat Oncol Biol Phys 2001;51:766-774.

86 Wakelkamp IM, Tan H, Saeed P, Schlingemann RO, Verbraak FD, Blank LE, Prummel MF, Wiersinga WM: Orbital irradiation for Graves' ophthalmopathy: is it safe? A longterm follow-up study. Ophthalmology 2004; 111:1557-1562.

87 Kahaly G, Schrezenmeir J, Krause U, Schweikert B, Meuer S, Muller W, Dennebaum R, Beyer J: Ciclosporin and prednisone v. prednisone in treatment of Graves' ophthalmopathy: a controlled, randomized and prospective study. Eur J Clin Invest 1986;16:415-422.
88 Prummel MF, Mourits MP, Berghout A, Krenning EP, van der Gaag R, Koornneef L, Wiersinga WM: Prednisone and cyclosporine in the treatment of severe Graves' ophthalmopathy. N Engl J Med 1989;321:1353-1359.

89 Dorner T, Lipsky PE: B cells: depletion or functional modulation in rheumatic diseases. Curr Opin Rheumatol 2014;26:228-236.

90 Salvi M, Vannucchi G, Beck-Peccoz P: Potential utility of rituximab for Graves' orbitopathy. J Clin Endocrinol Metab 2013;98:42914299.

91 El Fassi D, Banga JP, Gilbert JA, Padoa C, Hegedus L, Nielsen CH: Treatment of Graves' disease with rituximab specifically reduces the production of thyroid stimulating autoantibodies. Clin Immunol 2009;130:252-258.

92 Salvi M, Vannucchi G, Campi I, Rossi S, Bonara P, Sbrozzi F, Guastella C, Avignone S, Pirola G, Ratiglia R, Beck-Peccoz P: Efficacy of rituximab treatment for thyroid-associated ophthalmopathy as a result of intraorbital Bcell depletion in one patient unresponsive to steroid immunosuppression. Eur J Endocrinol 2006; 154:511-517.

93 Salvi M, Vannucchi G, Campi I, Curro N, Dazzi D, Simonetta S, Bonara P, Rossi S, Sina C, Guastella C, Ratiglia R, Beck-Peccoz P: Treatment of Graves' disease and associated ophthalmopathy with the anti-CD20 monoclonal antibody rituximab: an open study. Eur J Endocrinol 2007;156:33-40.

94 Salvi M, Vannucchi G, Curro N, Campi I, Covelli D, Dazzi D, Simonetta S, Guastella C, Pignataro L, Avignone S, Beck-Peccoz P: Efficacy of B-cell targeted therapy with rituximab in patients with active moderate to severe Graves' orbitopathy: a randomized controlled study. J Clin Endocrinol Metab 2015; 100:422-431.

95 Salvi M, Vannucchi G, Curro N, Introna M, Rossi S, Bonara P, Covelli D, Dazzi D, Guastella C, Pignataro L, Ratiglia R, Golay J, BeckPeccoz P: Small dose of rituximab for Graves orbitopathy: new insights into the mechanism of action. Arch Ophthalmol 2012;130:122124.

-96 Stan MN, Garrity JA, Carranza Leon BG, Prabin T, Bradley EA, Bahn RS: Randomized controlled trial of rituximab in patients with Graves' orbitopathy. J Clin Endocrinol Metab 2015;100:432-441.

97 Mitchell AL, Gan EH, Morris M, Johnson K, Neoh C, Dickinson AJ, Perros P, Pearce SH: The effect of $B$ cell depletion therapy on antiTSH receptor antibodies and clinical outcome in glucocorticoid-refractory Graves' orbitopathy. Clin Endocrinol (Oxf) 2013;79:437-442.

98 Khanna D, Chong KK, Afifiyan NF, Hwang CJ, Lee DK, Garneau HC, Goldberg RA, Darwin $\mathrm{CH}$, Smith TJ, Douglas RS: Rituximab treatment of patients with severe, corticosteroid-resistant thyroid-associated ophthalmopathy. Ophthalmology 2010;117:133.e2139.e2. 
$\$ 99$ Salvi M, Vannucchi G, Campi I, Curro N, Simonetta S, Covelli D, Pignataro L, Guastella C, Rossi S, Bonara P, Dazzi D, Ratiglia $\mathrm{R}$, Beck-Peccoz P: Rituximab treatment in a patient with severe thyroid-associated ophthalmopathy: effects on orbital lymphocytic infiltrates. Clin Immunol 2009;131:360365.

100 Krassas GE, Stafilidou A, Boboridis KG: Failure of rituximab treatment in a case of severe thyroid ophthalmopathy unresponsive to steroids. Clin Endocrinol (Oxf) 2010; 72:853-855.

101 Descotes J: Immunotoxicity of monoclonal antibodies. MAbs 2009;1:104-111.

102 van Vollenhoven RF, Emery P, Bingham CO 3rd, Keystone EC, Fleischmann RM, Furst DE, Tyson N, Collinson N, Lehane PB: Long-term safety of rituximab in rheumatoid arthritis: 9.5-year follow-up of the global clinical trial programme with a focus on adverse events of interest in RA patients. Ann Rheum Dis 2013;72:1496-1502.

103 Molloy ES, Calabrese LH: Progressive multifocal leukoencephalopathy in patients with rheumatic diseases: are patients with systemic lupus erythematosus at particular risk? Autoimmun Rev 2008;8:144-146.

104 Stiggelbout AM, Van der Weijden T, De Wit MPT, Frosch D, Légaré F, Montori VM, Elwyn G: Shared decision making: really putting patients at the centre of healthcare. BMJ 2012;344:e256.

105 Alkawas AA, Hussein AM, Shahien EA: Orbital steroid injection versus oral steroid therapy in management of thyroid-related ophthalmopathy. Clin Experiment Ophthalmol 2010;38:692-697.

106 Ebner R, Devoto MH, Weil D, Bordaberry M, Mir C, Martinez H, Bonelli L, Niepomniszcze $\mathrm{H}$ : Treatment of thyroid associated ophthalmopathy with periocular injections of triamcinolone. Br J Ophthalmol 2004;88: 1380-1386.

107 Lee SJ, Rim TH, Jang SY, Kim CY, Shin DY, Lee EJ, Lee SY, Yoon JS: Treatment of upper eyelid retraction related to thyroid-associated ophthalmopathy using subconjunctival triamcinolone injections. Graefes Arch Clin Exp Ophthalmol 2013;251:261-270.

-108 Perros P, Weightman DR, Crombie AL, Kendall-Taylor P: Azathioprine in the treatment of thyroid-associated ophthalmopathy. Acta Endocrinol (Copenh) 1990;122: 8-12.

109 Kahaly G, Lieb W, Muller-Forell W, Mainberger M, Beyer J, Vollmar J, Staiger C: Ciamexone in endocrine orbitopathy. A randomized double-blind, placebo-controlled study. Acta Endocrinol (Copenh) 1990;122: 13-21.
110 Dickinson AJ, Vaidya B, Miller M, Coulthard A, Perros P, Baister E, Andrews CD, Hesse L, Heverhagen JT, Heufelder AE, KendallTaylor P: Double-blind, placebo-controlled trial of octreotide long-acting repeatable (LAR) in thyroid-associated ophthalmopathy. J Clin Endocrinol Metab 2004;89:59105915.

111 Wemeau JL, Caron P, Beckers A, Rohmer V, Orgiazzi J, Borson-Chazot F, Nocaudie M, Perimenis P, Bisot-Locard S, Bourdeix I, Dejager S: Octreotide (long-acting release formulation) treatment in patients with Graves' orbitopathy: clinical results of a four-month, randomized, placebo-controlled, doubleblind study. J Clin Endocrinol Metab 2005; 90:841-848.

112 Chang TC, Liao SL: Slow-release lanreotide in Graves' ophthalmopathy: a double-blind randomized, placebo-controlled clinical trial. J Endocrinol Invest 2006;29:413-422.

-113 Stan MN, Garrity JA, Bradley EA, Woog JJ, Bahn MM, Brennan MD, Bryant SC, Achenbach SJ, Bahn RS: Randomized, doubleblind, placebo-controlled trial of long-acting release octreotide for treatment of Graves' ophthalmopathy. J Clin Endocrinol Metab 2006;91:4817-4824.

114 Antonelli A, Saracino A, Alberti B, Canapicchi R, Cartei F, Lepri A, Laddaga M, Baschieri L: High-dose intravenous immunoglobulin treatment in Graves' ophthalmopathy. Acta Endocrinol (Copenh) 1992; 126:13-23.

115 Kahaly GJ, Pitz S, Muller-Forell W, Hommel G: Randomized trial of intravenous immunoglobulins versus prednisolone in Graves' ophthalmopathy. Clin Exp Immunol 1996; 106:197-202.

116 Kazim M, Gold KG: A review of surgical techniques to correct upper eyelid retraction associated with thyroid eye disease. Curr Opin Ophthalmol 2011;22:391-393.

117 Baldeschi L: Rehabilitative surgery; in Wiersinga WM, Kahaly GJ (eds): Graves' Orbitopathy. A Multidisciplinary Approach Questions and Answers, ed 2. Basel, Karger, 2010, pp 167-170.

118 Boboridis KG, Uddin J, Mikropoulos DG, Bunce C, Mangouritsas G, Voudouragkaki IC, Konstas AG: Critical appraisal on orbital decompression for thyroid eye disease: a systematic review and literature search. Adv Ther 2015;32:595-611.

119 Baldeschi L, Wakelkamp IM, Lindeboom R, Prummel MF, Wiersinga WM: Early versus late orbital decompression in Graves' orbitopathy: a retrospective study in 125 patients. Ophthalmology 2006;113:874-878.

120 Baldeschi L, Macandie K, Koetsier E, Blank LECM, Wiersinga WM: The influence of previous orbital irradiation on the outcome of rehabilitative decompression surgery in Graves orbitopathy. Am J Ophthalmol 2008; 145:534-540.
121 Baldeschi L: Orbital decompression; in Wiersinga WM, Kahaly GJ (eds): Graves' Orbitopathy. A Multidisciplinary Approach - Questions and Answers, ed 2. Basel, Karger, 2010, pp 171-178.

122 Baldeschi L: Functional and rehabilitative surgery of Graves' orbitopathy; in Spaeth GL (ed): Ophthalmic Surgery: Principles and Practice, Atlas and Textbook, ed 4. Philadelphia, Elsevier, 2011, pp 424-440.

123 Eckstein A, Esser J: Surgical management of extraocular muscle dysfunction in patients with GO; in Bahn RS (ed): Graves' Disease. New York, Springer, 2015, pp 287-299.

124 Neoh C, Eckstein A: Eyelid surgery; in Wiersinga WM, Kahaly GJ (eds): Graves' Orbitopathy: A Multidisciplinary Approach Questions and Answers, ed 2. Basel, Karger, 2010, pp 200-210.

125 Wakelkamp IM, Baldeschi L, Saeed P, Mourits MP, Prummel MF, Wiersinga WM: Surgical or medical decompression as a firstline treatment of optic neuropathy in Graves' ophthalmopathy? A randomized controlled trial. Clin Endocrinol (Oxf) 2005;63:323328.

126 Bartalena L, Fatourechi V: Extrathyroidal manifestations of Graves' disease: a 2014 update. J Endocrinol Invest 2014;37:691-700.

127 Ponto KA, Hommel G, Pitz S, Elflein H, Pfeiffer N, Kahaly GJ: Quality of life in a German Graves' orbitopathy population. Am J Ophthalmol 2011;152:483.e1-490.e1.

128 Gerding MN, Terwee CB, Dekker FW, Koornneef L, Prummel MF, Wiersinga WM: Quality of life in patients with Graves' ophthalmopathy is markedly decreased: measurement by the medical outcomes study instrument. Thyroid 1997;7:885-889.

129 Graves' orbitopathy: improving outcomes for thyroid eye disease - the Amsterdam Declaration. Thyroid 2010;20:351-352.

130 Bahn RS: Graves'ophthalmopathy. N Engl J Med 2010;362:726-738.

131 Smith TJ, Hegedus L, Douglas RS: Role of insulin-like growth factor-1 (IGF-1) pathway in the pathogenesis of Graves' orbitopathy. Best Pract Res Clin Endocrinol Metab 2012;26:291-302.

132 Wiersinga WM: Autoimmunity in Graves' ophthalmopathy: the result of an unfortunate marriage between TSH receptors and IGF-1 receptors? J Clin Endocrinol Metab 2011;96:2386-2394.

133 Bartalena L: Graves' orbitopathy: imperfect treatments for a rare disease. Eur Thyroid J 2013;2:259-269.

134 Perez-Moreiras JV, Alvarez-Lopez A, Gomez EC: Treatment of active corticosteroidresistant Graves' orbitopathy. Ophthal Plast Reconstr Surg 2014;30:162-167. 